\title{
The Timing of Seasonal Growth is Influenced by Sunlight
}

\author{
Lars Gelander, Johan Karlberg and Kerstin Albertsson-Wikland
}

International Pediatric Growth Research Center, Department of Pediatrics, University of Göteborg (LG, KAW), Göteborg, Sweden and Department of Pediatrics, Queen Mary Hospital, University of Hong Kong (LG, $J K)$, Hong Kong

Key words: seasonality, short-term growth, childhood, height, lower leg length, sunlight

\section{Introduction}

During the childhood years there is a seasonal variation in height gain with an acceleration during the spring-summer time, at least in the northern hemisphere (1). A similar, but more distinct seasonal variation in growth velocity has been reported for lower leg length (LLL) (2). One reason for that the seasonality is more clear for LLL than for height is that LLL measurements have a low rate of technical error $(3,4)$. It is not exactly known why there is a seasonal pattern in the childhood growth rate, although it seems to be related to the dark-light cycle. For instance, the variation in the growth rate in blind children does not synchronise with the dark-light cycle (5). In this study we aimed to compare the seasonal growth pattern in normal children in two different years and to relate any between-yearseasonal differences to the number of hours of sunlight.

\section{Subjects}

In 1985 we followed-up 74 healthy chil-

Correspondence: Dr. Lars Gelander, International Pediatric Growth Research Center, Department of Pediatrics, University of Göteborg, Göteborg Sweden dren at 1-2 weeks intervals except for the summer vacation. In 1993 another 114 healthy children were followed-up at one month intervals. In both studies the children came from Göteborg, Sweden, and they were between 8 and 12 years of age; in 1985 the mean age was 9.43 years $(\mathrm{SD}=0.95)$ and in $1993,9.98$ years $(\mathrm{SD}=0.89)$. The 143 children who were prepubertal during the study year were included in the analysis: 50 children in 1985 and 83 children in 1993.

\section{Methods}

Monthly lower leg length velocity (LLLV) was calculated from the mean of the last three out of four LLL measurements performed on one child at each measuring session. The monthly number of hours of sunshine in Göteborg was reported by the Swedish weather service.

\section{Results}

The monthly mean LLLV values and the monthly number of hours of sunshine are given for both years in Figs. 1 and 2. The mean annual LLLV was not significantly different ( $P>0.05$ ) between the two study years; in 1985 


\section{Gelander et al.}

the mean LLLV was $2.07 \mathrm{~cm} / \mathrm{y}(\mathrm{SD}=0.96)$ and in 1993 the mean was $2.05 \mathrm{~cm} / \mathrm{y}(\mathrm{SD}=0.33)$.

The monthly number of hours of sunshine was different between the two study years with higher values (20-30\%) in all months from March to June in 1993 (Fig. 2). The maximum monthly mean LLLV value also came earlier in the spring-summer period in 1993 than in 1985 (Fig. 1). In 1993 it came in March (mean=2.63 $\mathrm{cm} / \mathrm{y}, \mathrm{SD}=0.99$ ) and in 1985 in May (mean=2.38 $\mathrm{cm} / \mathrm{y}, \mathrm{SD}=1.03$ ). However, in 1993 there was a second increase in growth velocity in June with a mean value of $2.47 \mathrm{~cm} / \mathrm{y}(\mathrm{SD}=0.93)$. In this year the number of hours of sunlight increased earlier in the spring and reached 236 hours in March, with the highest value of 274 hours in May. The bivariate correlation coefficient between the number of sun hours per month and the monthly mean LLLV values was 0.49 $(\mathrm{P}<0.05)$ in 1985 and $0.63(\mathrm{P}<0.05)$ in 1993.

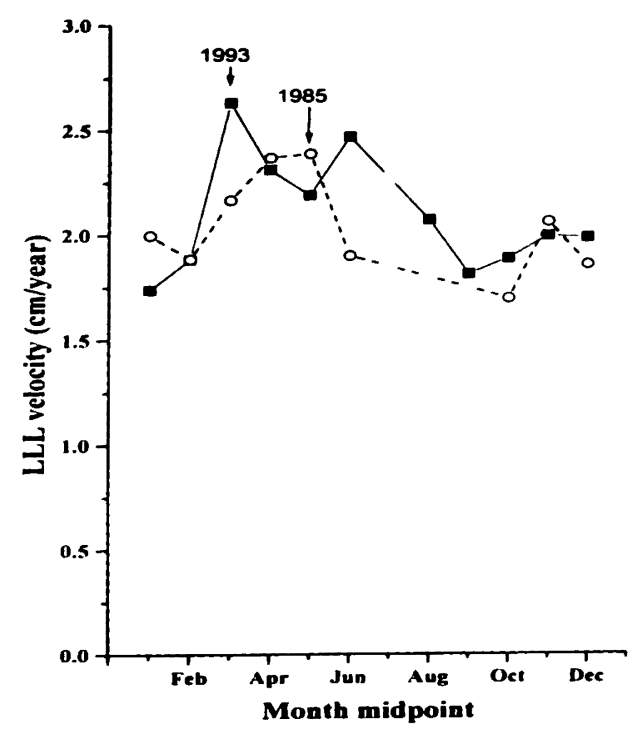

Fig. 1 Mean monthly lower leg length growth velocity for the two study years (1985 and 1993). The standard error of the monthly mean values varied between 0.17 and $0.31 \mathrm{~cm}$.

\section{Discussion}

We found a clear seasonal variation in mean lower leg length velocity during each of the two study years in healthy prepubertal Swedish children. However, the timing of the peak maximum monthly mean velocity values was different in the two years. For one of the years it came in March and for the other year it came in May, and this difference was associated with the difference in the number of sun hours between the two study years. Our results support the idea that seasonal variation in growth is related to the lightdark cycle $(1,5)$. When short-term growth is used as an outcome measure in controlled trials the normal seasonal variation in growth velocity must be considered (6). The betweenyear seasonal variation in the growth rate, as shown here, also points to the importance of

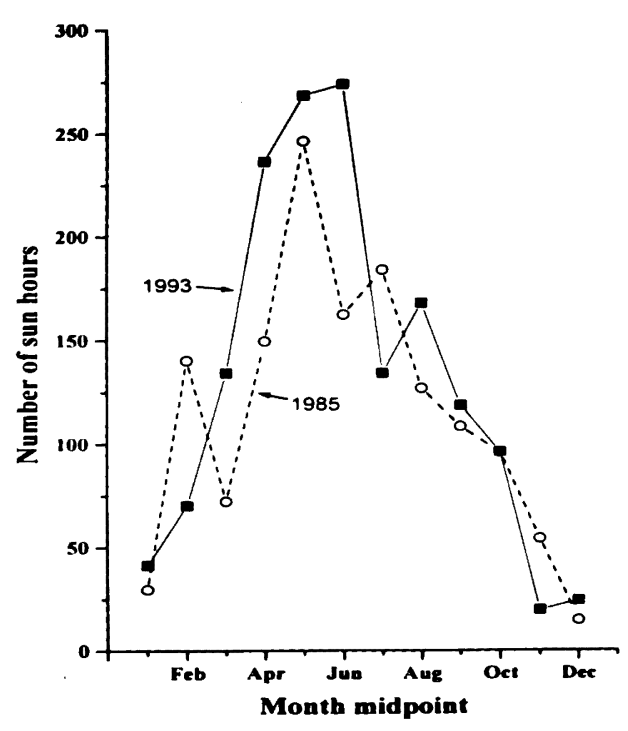

Fig. 2 The monthly hours of sunlight are shown for the years 1985 and 1993. 
using time-matched controls in such studies.

\section{Acknowledgements}

The authors would like to thank Ms Ingela Larsson for taking the knemometer measurements, and the pupils and teachers at Rosendalskolan, Göteborg, for their cooperation in this study. This work was supported by grants from Göderberg Foundation, Wilhelm and Martina Lundgren's Foundation, the First of May Flower Annual Campaign for Children's Health and the Medical Research Council (no 6465,7509 ).

\section{References}

1. Marshall WA. Evaluation of growth rate in height over periods of less than one year. Arch Dis Child 1971; 46: 414-20.

2. Gelander L, Karlberg J, Albertsson-
Wikland K. Seasonality in lower leg length and height velocity in prepubertal children. Acta Paediatr 1994 (in press).

3. Valk I, Langhout Chabloz A, Smaals AGH, Kloppenborg PWC, Cassorla FG, Schutte EAST. Accurate measurements of the lower leg length and the ulnar length and its application in short term growth measurement. Growth 1983; 47: 53-66.

4. Hermanussen $M$, Geiger-Benoit $K$, Burmeister J, Sippell WG. Knemometry in childhood: accuracy and standardization of a new technique of lower leg length measurement. Ann Hum Biol 1988; 15: 1-16.

5. Marshall WA, Swan AV. Seasonal variation in growth rates of normal and blind children. Hum Biol 1971; 43: 502-16.

6. Karlberg J, Gelander L, AlbertssonWikland K. Distinctions between shortterm and long-term growth studies. Acta Paediatr 1993; 82: 631-4. 